\title{
Homogeneous Charge Compression Ignition (HCCI) Engine Technology-A Review
}

\author{
Shamla A. Mulane ${ }^{+*}$ and S. D. Limaye ${ }^{\dagger}$ \\ †Department of Mechanical Engineering, Savitribai Phule Pune University, MIT College of Engineering, Pune, India
}

Accepted 03 March 2016, Available online 15 March 2016, Special Issue-4 (March 2016)

\begin{abstract}
The paper discusses about homogeneous charge compression ignition (HCCI) engine technology. Due to increasing emissions of greenhouse gases from automobile engines it is required to develop clean technology in automobiles with lower fuel consumption and higher efficiency for ambient air quality improvement, greenhouse gases reduction and energy security. The factors to be considered while designing this kind of technology are, high compression ratio, lean homogeneous air fuel mixture, complete and instantaneous combustion, which lead to homogeneous charge compression ignition (HCCI).HCCI combines the characteristics of Spark-Ignition (SI) and Compression Ignition (CI).HCCI engines can operate on gasoline, diesel fuel, and most alternative fuels. This paper reviews the technology involved in HCCI engine development, its advantages and disadvantages. The challenges involved in HCCI and the future developments in the same are also discussed in the paper.
\end{abstract}

Keywords: $H C C I, S I, C I, N O x, P M, C O, H C$.

\section{Introduction}

Internal combustion engines are the primary sources for transportation vehicles, marine ships, construction equipments and agricultural machineries among the others. Engines consume extremely large amount of fuel to produce power and emit poisonous or harmful exhaust gases which include $\mathrm{CO}, \mathrm{HC}, \mathrm{NOx}, \mathrm{PM}$ and $\mathrm{CO}_{2}$. Compression Ignition (CI) and Spark Ignition (SI) are two technologies established in automobile sector.SI an CI use fossil fuels and both have their own merits and demerits.

The characteristic feature of traditional SI engine is flame propagation for combustion. A conventional SI engine uses a homogeneous fuel/air mixture which is prepared in the intake port and then undergoes induction compression. SI engines with accurate control of air/fuel ratio and a three way catalytic convertor are very clean power producing machines but their efficiency is limited because of throttling, knocking and a lean flammability limit.

A conventional $\mathrm{CI}$ engine uses a heterogeneous fuel/ air mixture. In CI engines, only a fraction of air and fuel is premixed and burns fast, whereas for the larger part of the fuel, the time scale of evaporation diffusion, etc. is more than the chemical time scale. Hence, the air fuel mixture within the combustion chamber can be divided into two regions- the high fuel concentration regions and high temperature flame

*Corresponding author: Shamla A. Mulane regions. In the fuel rich regions, the rate of soot formation is high due to absence of oxygen $\left(\mathrm{O}_{2}\right)$. NOx is produced at high rates in the high temperature regions. $\mathrm{CI}$ engines are very efficient power producing machines but they have a constraint in the form of trade-off between oxides of nitrogen (NOx) and Particulate Matter (PM) emission.

HCCI represents the next major step beyond high efficiency CI (Compression Ignition) and Spark Ignition (SI) engines for use in transportation vehicles. In some regards, HCCI engines incorporate the best features of both spark ignition and compression ignition engines. Like an SI engine charge is well mixed which minimizes particulate emissions, and like a CI engine it is compression ignited and has no throttling losses, which leads to high efficiency. HCCI is potentially applicable to both light and heavy duty engines. Lightduty HCCI can run on gasoline and have the potential to match or exceed the efficiency of diesel fuelled $\mathrm{CI}$ engines, without major challenge of NOx and PM emission control for fuel refining capability. For heavyduty vehicles, successful development of the dieselfueled HCCI engine is an important alternative strategy in the event that $\mathrm{CI}$ engines cannot achieve future NOx and PM emission standards.

HCCI engines can operate on gasoline, diesel fuel, and most alternative fuels. HCCI engines have inherently low emissions of NOx and PM but relatively high emissions of hydrocarbon (HC) and carbon monoxide (CO). But, reducing $\mathrm{HC}$ and $\mathrm{CO}$ emissions is much easier than reducing NOx and PM from $\mathrm{Cl}$ 
engines. HCCI engine technology is the most promising technology in the future to reduce emissions and for cleaner environment.

\section{HCCI Combustion}

\section{HCCI principle}

In HCCI mode of combustion, the fuel and air are mixed prior to the start of the combustion and the mixture is auto-ignited spontaneously at multiple sites throughout the charge volume due to increase in temperature in the compression stroke. In this mode, the combustion process is arranged in such a way that the combustion takes place under very lean and dilute mixture conditions, which results in comparatively lower bulk temperature and localized combustion temperature, which therefore, considerably reduces the NOx emissions. Furthermore, unlike conventional CI combustion, in HCCI mode the fuel and air is well mixed (homogeneous). So, the absence of rich fuel regions in the combustion chamber results in considerable reduction in PM generation. Therefore, absence of locally high temperatures and a rich fuel-air mixture during combustion process, the simultaneous reduction of NOx and PM emissions is made possible.

\section{Working of HCCI Engine}

In an HCCI engine (which is based on the four-stroke Otto cycle), fuel delivery control is of paramount importance in controlling the combustion process. On the intake stroke, fuel is injected into each cylinder's combustion chamber via fuel injectors mounted directly in the cylinder head. This is achieved independently from air induction which takes place through the intake plenum. By the end of the intake stroke, fuel and air have been fully introduced and mixed in the cylinder's combustion chamber.

As the piston begins to move back up during the compression stroke, heat begins to build in the combustion chamber. When the piston reaches the end of this stroke, sufficient heat has accumulated to cause the fuel/air mixture to spontaneously combust (no spark is necessary) and force the piston down for the power stroke. Unlike conventional spark engines (and even diesels), the combustion process is a lean, low temperature and flameless release of energy across the entire combustion chamber. The entire fuel and air mixture is burned simultaneously producing equivalent power, but using much less fuel and releasing far fewer emissions in the process.

At the end of the power stroke, the piston reverses direction again and initiates the exhaust stroke, but before all of the exhaust gases can be evacuated, the exhaust valves close early, trapping some of the latent combustion heat. This heat is preserved, and a small quantity of fuel is injected into the combustion chamber for a pre-charge (to help control combustion temperatures and emissions) before the next intake stroke begins.

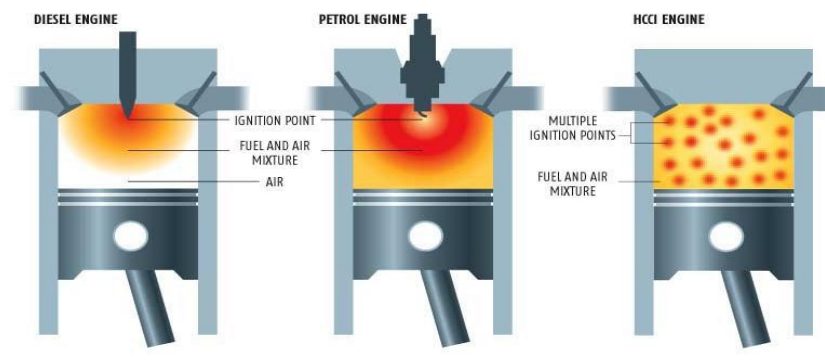

Fig.1Schematic diagram of HCCI

Few of the characteristic differences between conventional SI Engine and HCCI Engine and conventional Diesel Engine and HCCI Engine are shown in Table.1and Table.2respectively.

Table 1Comparison between conventional SI engine and HCCI engine

\begin{tabular}{|c|c|c|}
\hline Basics of comparison & SI engine & HCCI engine \\
\hline Efficiency & Less & More \\
\hline Throttle Losses & More & No \\
\hline Compression Ratios & Low & High \\
\hline Combustion Duration & More & Less \\
\hline NOx emissions & $\begin{array}{c}\text { Comparatively } \\
\text { low }\end{array}$ & Less \\
\hline
\end{tabular}

Table 1Comparison between conventional CI engine and HCCI engine

\begin{tabular}{|c|c|c|}
\hline $\begin{array}{c}\text { Basics of } \\
\text { comparison }\end{array}$ & CI engine & HCCI engine \\
\hline Efficiency & High & Equally high \\
\hline $\begin{array}{c}\text { Combustion } \\
\text { Temperatures }\end{array}$ & $1900-2100 \mathrm{~K}$ & $800-1100 \mathrm{~K}$ \\
\hline Cost & Comparatively high & Less \\
\hline $\begin{array}{c}\text { Combustion } \\
\text { Duration }\end{array}$ & More & Less \\
\hline $\begin{array}{c}\text { PM and NOx } \\
\text { emissions }\end{array}$ & More & Less \\
\hline
\end{tabular}

\section{Challenges}

The control of HCCI combustion is fundamentally more challenging than using a direct control mechanism such as a spark plug or fuel injector to dictate ignition timing, as in SI and CI engines. Nonetheless, HCCI engines have several inherent benefits as potential replacements for SI and CI engines in vehicles with conventional power trains. HCCI has thus far been incorporated in certain production DI diesel engines, enabled not only by a better understanding of the physical and chemical processes involved in this combustion mode but also by discovery of technical solution for practical applications of this new combustion mode. The main challenges that have kept HCCI from being applied to commercial engines can be stated as follows:

1) Ignition timing control over wide engine speedload ranges: It is widely recognized that HCCI combustion is driven by chemical kinetics and is 
therefore controlled by fuel physical and chemical properties as well as the temperature history of the fuel/air mixture. On the contrary, in-cylinder turbulence and mixing have little influence on combustion timing. As the ignition timing has been shown to be very sensitive to factors such as octane number, intake charge temperature, fuel/air equivalence ratio, mixture composition or EGR rate, and fuel composition, the most pressing task for HCCI implementation is to ensure that ignition occurs near TDC under variable working conditions.

2) Combustion rate control from high- to full-load engine operation: HCCI combustion has been demonstrated to operate well at low to medium loads but difficulties have been encountered at high loads. Combustion can become very rapid and intense, causing unacceptable noise, potential engine damage, and eventually, unacceptable levels of NOx emissions. Additional work is needed to develop methods that reduce the heat release rate under high-load operation conditions to prevent excessive noise or engine damage.

3) Cold start capacity: HCCI ignition is very sensitive to intake charge temperature, and minor variations alter combustion phasing significantly. Furthermore, the initial temperature required to achieve self-ignition varies with fuel properties and operation conditions. Under cold start and idle operating conditions, the compressed gas temperature will be reduced because the charge receives no preheating from the intake manifold and is rapidly cooled by heat transferred to the cold combustion chamber walls. Without some compensatory mechanism, low compressed charge temperatures could prevent an HCCI engine from firing.

4) Higher levels of HC and CO: HCCI combustion produces inherently low emissions of NOx and PM at lower engine loads but relatively high emissions of HC and CO at low to medium loads as well as high emissions of NOx under large loads. Thus, it is necessary to develop emission control systems and control strategies to overcome the challenge of excessive $\mathrm{HC}$ and $\mathrm{CO}$ emissions, particularly at low loads.

5) Mixture preparation: This is particularly important for poor volatility diesel-fueled HCCI combustion. The main goals here are to avoid wall impingement, to promote fuel vaporization and air mixing so as to limit PM and HC emissions, and to prevent oil dilution.

6) Relatively higher pressure-rise rate and severe combustion noise: Because the HCCI combustion rate is so high, ignition occurs simultaneously throughout the combustion chamber, producing a high pressure-rise rate and high-frequency noise or intensive ringing when compared to the behaviour of a conventional DICI or SI engine, especially under a large equivalence ratio.
7) Engine control strategies and systems: Additional work is needed with regards to the development of a new methodology for feedback and closed-loop control of fuel and air systems, advanced control theory and control arithmetic, next-generation combustion sensors, and next-generation software and hardware specialized for HCCI combustion in order to optimize combustion over wide loadspeed ranges.

\section{Recent developments in HCCI}

Recent developments in the HCCI technology have given very positive results to overcome the limitations of this technology. The technology has huge scope of use and it is used in wide range of industries, which makes it promising technology for the coming generations. Automobile giants like GM, Ford and Cummins have been exploring the possibilities in the HCCI technology for more than 15 years. General Motors has started educational programs in various universities to promote the research work in this technology. HCCI has also enabled engineers to experiment with different blend of fuel mixture so that performance and efficiency of HCCI engines can be tested with different combinations of non-conventional fuels.

General Motors has demonstrated Opel Vectra and Saturn Aura with modified HCCI engines. MercedesBenz has developed a prototype engine called Dies Otto, with controlled auto ignition. It was displayed in F-700 concept car at the 2007 Frankfurt Auto Show Volkswagon are developing two types of engine for HCCI operation. The first called Combined Combustion System or CCS is based on the VW group 2.0-litre diesel engine but uses homogeneous intake charge rather than traditional diesel injection.

Table 1Comparison between conventional CI engine and HCCI engine

\begin{tabular}{|c|c|c|c|}
\hline Company & Company & Technology & $\begin{array}{c}\frac{\text { Estimated }}{\underline{\text { Year of }}} \\
\text { Commercializa } \\
\underline{\text { tion }}\end{array}$ \\
\hline \multirow[t]{2}{*}{\begin{tabular}{|l|} 
General \\
Motors
\end{tabular}} & $\begin{array}{l}\text { Saturn- } \\
\text { Aura }\end{array}$ & $\mathrm{pHCCl}$ & $\begin{array}{l}\text { Test Vehicle is } \\
\text { on the Road. }\end{array}$ \\
\hline & $\begin{array}{l}\text { Opel- } \\
\text { Vectra }\end{array}$ & $\mathrm{pHCCl}$ & 2015 \\
\hline Mercedes & Dies-otto & $\mathrm{PHCCl}$ & $\begin{array}{l}\text { Test Vehicle is } \\
\text { on the Road. }\end{array}$ \\
\hline \multirow[t]{2}{*}{$\begin{array}{l}\text { Volkswag } \\
\text { en }\end{array}$} & Touran & $\begin{array}{c}\text { CCS(Combined } \\
\text { Combustion Spark) }\end{array}$ & 2015 \\
\hline & & $\begin{array}{c}\mathrm{GCl} \text { (Gasoline } \\
\text { Compression } \\
\text { Ignition) }\end{array}$ & \\
\hline Ford & & $\mathrm{pHCCl}$ & 2015 \\
\hline
\end{tabular}

In May 2008, General Motors gave Auto Express access to a Vauxhall Insignia prototype fitted with a 2.2-litre HCCI engine, which will be offered alongside their ecoFLEX range of small-capacity, turbocharged petrol and diesel engines when the car goes into production. Official figures are not available, but fuel economy is 
expected to be in region of $43 \mathrm{mpg}$ (miles per gallon) with carbon dioxide emissions of about 150 grams per kilometer, improving on the $37 \mathrm{mpg}$ and $180 \mathrm{~g} / \mathrm{km}$ produced by the current 2.2-litre petrol engine. The new engine operates in HCCI mode at low speeds or when cruising, switching to conventional sparkignition when the throttle is opened.

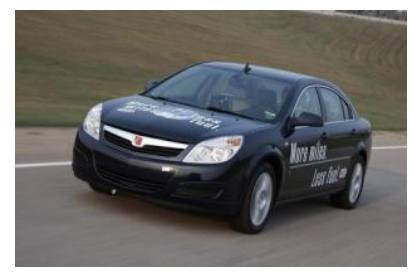

Fig.3: Prototype HCCI car from Saturn

\section{Conclusion}

A high efficiency, gasoline fueled HCCI engine represents a major step beyond SI engines for light duty vehicles. The HCCI combustion engines have the potential to reduce the NOx and PM emissions simultaneously, while maintaining the thermal efficiency close to that of conventional diesel engine. Also, HCCI engines would probably cost less than CI engines because HCCI engines would likely use lowerpressure fuel-injection equipment and the combustion characteristics of HCCI would potentially emission control devices that depend less on scarce and expensive precious metals.

But in HCCI combustion there are any challenges such as difficulty in combustion planning control, misfire at low and knocking at high loads, cold start problem, difficulty in homogeneous mixture preparation, high rate of pressure rise and high level of noise, high level of $\mathrm{HC}, \mathrm{CO}$ combustion etc. the homogeneous mixture preparation and auto-ignition control are the main issues of HCCI combustion. Two fundamentally different approaches to control HCCI combustion phasing are possible
- Altering the mixture propensity for autoignition.

- Altering the time-temperature history to which the mixture is exposed.

HCCI is a combustion concept which is developed in response to the need of lower NOx \& PM emission and efficiency. It can substantially overcome all the problems but requires a lot of improvement. A viable method for combustion control problem in production has not yet been identified.

\section{References}

P.Venkatrama (2013), Homogeneous Charge Compression Ignition (HCCI) Engine, International Journal of Engineering Research And Technology (IJERT) ISSN:2278-0181 Vol.2 Issue 2, February-2013

P.V.Ramana, D Maheshwar, B. Unmeneshwar Gowd (2015), Review on Research and development of HCCI technology, International Journal of IT, Engineering And Applied Sciences Research (IJIEASR) Volume 4, No.5, May 2015

Jack Hunicz, Pawel Krzaczek (2016), Detailed Speciation of Emissions from Low-Temperature Combustion in a Gasoline HCCI Engine, Poland Journal Environmental Studies Volume 25 No.1 (2016), 137-145

Anku kumar singh, M.K. Paswan (2014), Homogeneous Charge Compression Ignition Engine, International Journal Of Mechanical Engineering And Robotics Research (IJMERR) ISSN 2278-0149 Vol.3, No.1, January 2014

Krzysztof Motyl, Tadeusz J. Rychter (2003), HCCI Engine - A Preliminary Analysis Journal of KONES Internal Combustion Engines 2003, Vol. 10, 3-4

Pravin Kumar, A.Rehman Homogeneous Charge Compression Ignition (HCCI) Combustion Engine- A Review IOSR Journal of Mechanical And Civil Engineering e-ISSN:2278-1648, pISSN: 2320-334X, Volume 11, Issue 6, Ver.II (Nov.- Dec. 2014), PP 47-67 